\title{
Universiteit
}

Leiden

The Netherlands

\section{Wh-question or wh-declarative? Prosody makes the difference}

Yang, Y.; Gryllia, S.; Cheng, L.L.

\section{Citation}

Yang, Y., Gryllia, S., \& Cheng, L. L. (2020). Wh-question or wh-declarative? Prosody makes the difference. Speech Communication, 118, 21-32. doi:10.1016/j.specom.2020.02.002

Version: $\quad$ Publisher's Version

License: $\quad$ Licensed under Article 25fa Copyright Act/Law (Amendment Taverne)

Downloaded from: https://hdl.handle.net/1887/3200898

Note: To cite this publication please use the final published version (if applicable). 


\title{
Wh-question or wh-declarative? Prosody makes the difference
}

\author{
Yang Yang a,b,*, Stella Gryllia ${ }^{\mathrm{b}}$, Lisa Lai-Shen Cheng ${ }^{\mathrm{b}}$ \\ ${ }^{\text {a }}$ Center for Linguistics and Applied Linguistics, Guangdong University of Foreign Studies, China \\ ${ }^{\mathrm{b}}$ Leiden University Centre for Linguistics, The Netherlands
}

\section{A R T I C L E I N F O}

\section{Keywords:}

Wh-question

Wh-declarative

Prosody

Clause type

Ambiguity

\begin{abstract}
A B S T R A C T
Mandarin wh-words can have question or non-question (e.g., existential, universal quantificational) interpretations. Their interpretations in a sentence are usually not ambiguous, as the distinct interpretations need to be licensed by particular items/contexts. The starting point of our study concerns a case which allows the wh-words to remain ambiguous in a sentence: wh-words such as shénme appearing with diănr. After empirically confirming that such sentences are indeed ambiguous (Study 1), we turn to the question of whether and how prosody helps disambiguate such sentences. Our production experiment (Study 2) shows that wh-declaratives differ from wh-questions in terms of prosodic properties already from the clause onset. Wh-declaratives are longer than $w h$ questions starting from the subject and the pattern reverses at the wh-word; wh-declaratives are lower in F0 and smaller in F0 range than wh-questions at the wh-word and there is a F0 range compression in the post-wh-word region in wh-questions; wh-declaratives show larger intensity range than wh-questions at the verb and the pattern reverses at the wh-word. An implication of this study concerns the focal status of $w h$-words in wh-questions and wh-declaratives: wh-words are foci in wh-questions but cannot be foci in wh-declaratives.
\end{abstract}

\section{Introduction}

\subsection{Wh-words in Mandarin Chinese}

Mandarin Chinese is a wh-in-situ language (Huang, 1982), in which question words (i.e., wh-words) remain at their base position, as illustrated in (1). (1a) is an ordinary information-seeking question, where the wh-word shénme 'what' corresponds to the direct object of the sentence. The wh-word shénme occupies the same position as the direct object shu 'book' in the declarative counterpart in (1b).

$\begin{array}{llll}\text { (1) a. Zhāng Sān } & \text { mǎi-le } & \text { shénme? } & \\ \text { Zhang San } & \text { buy-PERF } & \text { what } & \\ \text { 'What did Zhang San buy?' } & & \text { [wh-question] } \\ \text { b. Zhāng Sān mǎi-le } & \text { shū. } & \\ \text { Zhang San } \quad \text { buy-PERF } & \text { book } & \\ \text { 'Zhang San bought a book.' } & & \text { [declarative] }\end{array}$

Besides the interrogative interpretation, wh-words in Mandarin (as in Japanese and Korean) can receive a universal ('everything') or existential ('something') interpretation, subject to different licensors/quantifiers, as shown in (2a) and (2b). In (2a), the universal interpretation is licensed by the maximality operator dōu (see Giannakidou and Cheng, 2006; Cheng, 2009 for the analysis of $d \bar{o} u$ as a maximality operator), while in (2b), the existential interpretation is triggered by the yes-no question particle ma.

$$
\begin{array}{llll}
\text { (2) a. Zhāng Sān shénme dōu } & \text { mǎi. } & \\
\text { Zhang San SHENME all } & \text { buy } & \\
\text { 'Zhang San buys everything.' } & & \text { [universal] } \\
\text { b. Zhāng Sān măi-le shénme } & \text { ma? } & \\
\text { Zhang San buy-PERF SHENME }{ }^{1} & \text { yes-no particle } & \\
\text { 'Did Zhang San buy anything?' } & & \text { [existential] }
\end{array}
$$

Although the wh-words can have different interpretations, the interpretation of wh-words in Mandarin in each sentence is in general unambiguous, as the different interpretations are connected to different licensors. In the absence of any overt licensors, a wh-word like shénme is typically interpreted as an interrogative word ('what') and the sentence is a wh-question, as ( $1 \mathrm{a})$. In the case most relevant for the current study, i.e., the existential interpretation of wh-words (e.g., 'something' for shénme), aside from the yes-no question environment (2b), the existential interpretation of the wh-word ('something') has been shown to be licensed by sentences containing negation, conditionals, and epistemic modalities. These sentences are referred to as "nonveridical sen-

\footnotetext{
${ }^{1}$ From here on, we gloss shénme simply as SHENME, as it can have interrogative and non-interrogative interpretations.

${ }^{2}$ We gloss $m a$ as yes-no particle, the particle for yes-no questions.
}

\footnotetext{
* Corresponding author at: Center for Linguistics and Applied Linguistics, Guangdong University of Foreign Studies, Room 103, Building 8, No. 2 Baiyun Avenue North, Baiyun District, Guangzhou 510420, China.

E-mail address: yangyanggw@gdufs.edu.cn (Y. Yang).
} 
tences/contexts". That is, in these sentences/contexts, the truth of a proposition (e.g. 'Zhang San bought things') cannot be entailed, as in (2b) (see Li, 1992; Lin, 1998, 2014; Huang, 2018 for details).

\subsection{An ambiguous case in interpreting wh-words}

Though most cases of $w h$-words are unambiguous, there are a few instances where the $w h$-word is in fact ambiguous between a declarative and question interpretation. Consider the sentence in (3), which contains an adverb zuótiān 'yesterday' and the perfective marker le. This is a typical veridical sentence, in which the truth of the proposition (e.g. 'Zhang San bought things') is entailed. Following previous analyses of existential interpretation of $w h$-words (as mentioned above), where the existential interpretation is only licensed in nonveridical contexts, we expect the wh-word in (3) to only have an interrogative interpretation ('what') as in (3i).

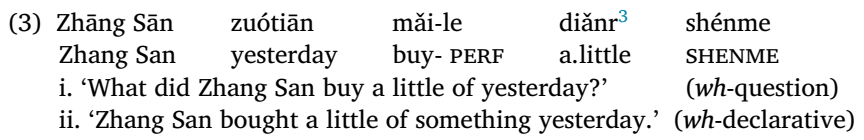

Nonetheless, our observation in (3) runs counter to the existing literature. In particular, native speaker informants consider the wh-word in (3) to also have an existential reading (i.e., 'something') as in (3ii). This means that the sentence in (3) is in fact ambiguous; it can be interpreted as a wh-question or as a declarative. In this paper we use the term wh-declarative to refer to a declarative sentence which contains a wh-word. To determine whether (3) is indeed ambiguous between a $w h$-question interpretation and a $w h$-declarative interpretation, a solid empirical study is needed, which we conducted, and is reported in Section 2.

\subsection{The role of prosody in distinguishing questions and declaratives}

With ambiguous sentences like (3), the question also arises whether and how the two interpretations or clause types (wh-questions and whdeclaratives) are disambiguated by speakers.

It is known that context can play a role in resolving ambiguities or differentiating interpretations or clause types (Spivey-Knowlton et al., 1993). Nonetheless, when an utterance such as (3) is used out of context, how can the wh-question interpretation be distinguished from the $w h$ declarative interpretation? Previous studies have shown that prosody can function as the defining feature of questions in the absence of an overt syntactic interrogativity marker (e.g. Bolinger, 1978; Ohala, 1983, 1984). In other words, when declaratives are string identical to questions, prosody plays a critical role in marking the different clause types (Jun and Oh, 1996; Frota, 2002; Face, 2004; Vion and Colas, 2006; Baltazani, 2007, among others). In Mandarin, prosodic markings are often investigated from either a global perspective like the sentence F0 curve/contour or local prosodic features like duration, F0 (range) or intensity (range) on the syllable or word level or a combination of both (Shi, 1980; Shen, 1994; Yuan, 2004; Liu, 2009; Jiang and Chen, 2011). In Mandarin, polar questions can also be string identical to declaratives, and the former are marked with a higher sentence F0 curve as compared with their declarative counterparts (Shi, 1980; Shen, 1990, 1994; Yuan, 2004, 2006; Jiang and Chen, 2011, among others) and the biggest F0 difference between the two clause types often lies in the final syllable (Yuan, 2004, 2006).

The above studies on the role of prosody in marking different clause types are centered on polar questions. However, it remains unclear

\footnotetext{
${ }^{3}$ Diănr is considered to be a quantifier (Zhang, 2013) or a determiner with existential force (Tsai, 2010), denoting the meaning of "a small quantity". It functions as a licensor for the existential interpretation of shénme. Different from Taiwan Mandarin diăn |tien|, the Beijing Mandarin diănr |tier| in our case is Erhuayin, namely, it has an R-ending Retroflexion, a very typical retroflex phenomenon in Beijing Mandarin (Huang and Liao, 2002).
}

whether and how wh-declaratives and wh-questions as in (3) are prosodically marked and distinguished. Studies have shown that Korean (also a wh-in-situ language with wh-words with similar properties as Mandarin) utilizes pitch accent and prosodic phrasing to differentiate $w h$-questions and declaratives containing $w h$-words: normally, a wh-interrogative bears a high-pitch accent and a wh-existential bears a low-pitch accent; wh-questions are characterized by a post-wh-word de-phrasing, namely, a deletion of accentual phrasings following the wh-word (Jun and Oh, 1996; Shin, 2005; Yun, 2012). In Mandarin, so far, only two studies investigate the prosody of the two relevant clause types (Dong, 2009; Liu et al., 2016). Below we review them one by one.

Dong (2009) compares wh-questions and wh-declaratives in terms of F0, although not on string identical cases. As illustrated in (4), the wh-word shéi is interpreted as a question word 'who' in (4a) and as an existential in (4b) meaning 'someone'. Dong's results show that wh-word is the most prosodically prominent item in wh-questions as shown by its expanded pitch range, while in contrast it has a compressed pitch contour in $w h$-declaratives; instead, the verb bears the prosodic prominence with expanded pitch range in wh-declaratives.

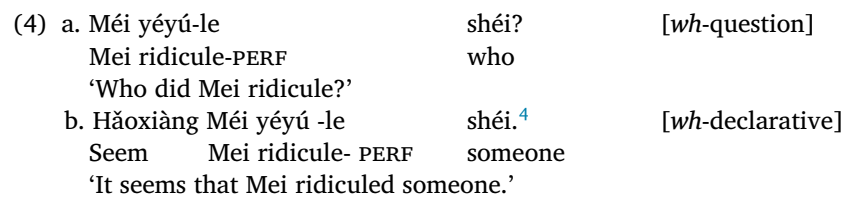

Dong's study focusses on F0. Nonetheless, duration (and intensity) can also be informative prosodic cues to investigate (Shen, 1993; Chuang and Fon, 2010).

Liu et al. (2016) investigate the prosodic marking of wh-questions with the string identical $w h$-declaratives. They compare the two clause types from the perspective of both local prosodic features (prosodic properties of each word) and global prosodic features (sentence F0 curve). The examples (5a-b) illustrate the comparisons between the two clause types.
(5) a. Zhāng Sān dǎsuàn chī diănr ${ }^{5}$ shénme gāo? Zhang San intend.to eat a.little SHENME cake 'What kind of cake does Zhang San intend to eat?' b. Zhāng Sān dăsuàn chī diănr shénme gāo. Zhang San intend.to eat a.little SHENME cake 'Zhang San intends to eat whatever cake.'
[wh-question]
[wh-declarative]

Similar to Dong (2009), Liu et al. found that the wh-word in $w h$ questions bears extended pitch range and higher pitch register than its counterpart in wh-declaratives. However, unlike Dong (2009), Liu et al. do not find any prosodic differences at the verb between the two clause types in (5), and the prominent word in both clause types is mostly at the sentence final position (e.g. gāo). Furthermore, it should be noted that, in Liu et al.'s study, the wh-word shénme is a modifier of the object noun 'cake', as shown in (5), while Dong uses the wh-word as the object, as shown in (4). In addition, Liu et al.'s results are based on a pilot study with a small sample of speakers (8 speakers). Hence Liu et al.'s results should be considered cautiously.

Based on these very limited studies, we can only conclude that whwords have higher pitch and expanded pitch range when used as question words as compared with their existential counterparts. A knowledge gap remains as we cannot draw a clear picture with respect to how prosody can distinguish the two clause types, namely wh-questions and wh-declaratives. In particular, at which point in the sentence does a wh-

\footnotetext{
${ }^{4}$ Haoxiang '(it) seems' in this sentence ensures that the sentence is nonveridical, yielding the environment for existential interpretation of the $w h$-word.

5 Note that the stimuli in Liu et al. (2016) also contain the quantifier diănr, as in our study. But their stimuli containing dăsuàn 'intend to' in (5b) yields a nonveridical context, which can license the existential reading of shénme. This differs from our observation concerning (3), which is a veridical context containing diǎnr.
} 
declarative begin to differ from a wh-question in terms of prosody, and in which prosodic properties (F0, duration or intensity) do they differ?

\subsection{Research questions}

In this paper, we scrutinize the prosody of wh-declaratives and $w h$ questions, addressing the following research questions:

$\mathrm{R}(1)$. In sentences containing $w h$-words, are the two interpretations (wh-declarative, wh-question) both available?

$\mathrm{R}(2)$. Is there a prosodic distinction between $w h$-questions from $w h$ declaratives? If yes, how do they differ?

The paper is organized as follows. In Section 2, we report the results of a reading study that investigated the availability of both a declarative and a question interpretation in sentences like (3), answering research question $\mathrm{R}(1)$. Section 3 presents the results of a production experiment on wh-questions and wh-declaratives, answering research question $\mathrm{R}(2)$. Section 4 concludes and examines the implications of the results found in the reading study and the production study.

\section{A reading study on $w h$-questions and $w h$-declaratives}

We have reported above that the veridical sentence in (3) containing a wh-word preceded by the quantifier diănr ('a little'), is observed to be ambiguous between a question interpretation and a declarative interpretation (wh-word shénme interpreted as an existential 'something'), which challenges previous analyses where the existential interpretation is licensed in nonveridical sentences only. To investigate whether our observation is empirically supported, we conducted a reading study where participants were asked to read silently $w h$-sentences containing wh-words preceded by diănr ('a little') as in example (3), and to finish them using a question mark or a full stop. Since no prosodic cues or previous contexts are given, we predict that participants will identify the wh-sentences as both questions and declaratives, due to the ambiguous status of the wh-word plus diănr.

\subsection{Participants}

Eighty-four native speakers of Beijing Mandarin (53 females and 31 males, $\bar{x}$ age $=20$ years old, $\mathrm{SD}=2.3$ ) were paid to participate in the reading experiment. All of them came from the northern part of Mainland China and at the time of testing were students at Tsinghua University. None of them reported speech problems or visual impairment. Prior to testing, informed written consent was obtained from each participant.

\subsection{Experimental materials}

We created a total of 40 stimuli. Half of the stimuli were ambiguous between an interrogative and a declarative interpretation (target stimuli), see (6a). The other half of the stimuli were unambiguous; they could be interpreted only as interrogatives (control stimuli), see (6b). As shown in (6), the target and control stimuli were string identical except for diănr 'a little', which was present in the target stimuli but absent in the control. To construct the stimuli we used the basic word order in Mandarin (Li, 1990): Subject (proper name, e.g. Féng Tāo), Adverb (e.g. zúotiān 'yesterday'), Verb (e.g. zùo 'make') + Perfective marker (le), (diănr), Direct Object (shénme 'what/something'), and Prepositional Phrase (e.g. gěi Wáng Yĩng 'to/for Wang Ying'). For the subject and the indirect object we used the commonly used disyllabic Chinese proper names. The length (the number of syllables) of all constituents was kept constant across stimuli.
[Target]

(6) a. Féng Tāo zúotiān zùo-le diănr shénme gěi Wáng Yīng Feng Tao yesterday make-PERF a.little SHENME for Wang Ying 'What did Feng Tao make for Wang Ying yesterday?' or [Control] 'Feng Tao yesterday made a little of something for Wang Ying.'

b. Féng Tāo zúotiān zùo-le shénme gěi Wáng Yīng

Feng Tao yesterday make-PERF what for Wang Ying

'What did Feng Tao make for Wang Ying yesterday?'

The target and control stimuli were intermingled with 120 fillers. The fillers consisted of 20 polar questions with $m a$ (i.e., yes-no question particle), 20 A-not-A questions ${ }^{6}$ and 80 declaratives. All stimuli lacked punctuation and were randomized for each participant.

\subsection{Procedure}

Participants were tested individually in a quiet room in Tsinghua University in Beijing, and the whole experiment lasted about $15 \mathrm{~min}$. The participants' were instructed to first read the stimulus on screen silently, and then to complete the sentence choosing a question mark or a full stop. The experiment was run on E-prime 2.0 (Psychology Software Tools) and was semi-self-paced. The procedure was as follows. A stimulus appeared on the computer screen and participants had a maximum of $5 \mathrm{~s}$ to read it silently. If participants read the stimulus faster than $5 \mathrm{~s}$, they could press the space bar and move to the next screen to indicate their response. If participants exceeded the $5 \mathrm{~s}$ time limit, the next screen appeared automatically. This next screen showed the two punctuation marks: a question mark (?) and a full stop (.) and participants had again $5 \mathrm{~s}$ to indicate their response. If participants exceeded the time limit of $5 \mathrm{~s}$, the next stimulus appeared automatically on screen. The question mark and the full stop were counter-balanced on screen to avoid any left or right preference by participants.

\subsection{Statistical analysis and results}

We obtained a total of 3350 responses (1673 responses for target stimuli, 1677 responses for control stimuli; there were 7 missing responses for target stimuli and 3 missing responses for control stimuli). We also extracted participants' stimuli reading time and response time respectively.

\subsubsection{Responses}

Participants interpreted the control stimuli (wh-sentences without diănr) as questions $93.1 \%$ of the time, while they interpreted the target stimuli ( $w h$-sentences with diănr) as questions $59.7 \%$ of the time, and as declaratives $40.3 \%$ of the time, see Fig. 1 . We found a significant association between the stimulus type (target or control) and the participants' responses, [ $\left.\mathrm{x}^{2}=518.91(1), p<0.001\right]$.

Moreover, we ran a mixed effects logistic regression using the glmer command in the lme4 package (Bates et al., 2015) in R (R Core Team, 2017) to investigate whether participants' responses can be predicted on the basis of the stimulus type. Specifically, we first ran a null model with participants' responses as a dependent variable, and participants and items as random factors. We then ran a model that included in addition the stimulus type as a fixed effect factor to see whether the model was improved. Finally, on the basis of the first two models that included participants' responses as a dependent variable, the stimulus type as a fixed-effect factor, and participants and items as random factors, allowing by-participant and by-item random intercepts, we ran another three models that in addition allowed by-participant or/and by-item random slopes for the stimulus type. Model fit was compared based on the likelihood ratio test (Pinheiro and Bates, 2000; Bolker et al., 2009) and the model which included by-participant and by-item random intercepts,

\footnotetext{
${ }^{6}$ A-not-A question is a type of polar question in Mandarin offering a choice between an affirmative sentence and its negative counterpart.
} 


\section{Table 1}

Summary of the results of the mixed effects logistic regression between participants' responses and the stimulus type.

\begin{tabular}{llll}
\hline Estimate $\beta$ & Std. Error & $z$ value & $p$ value \\
\hline-2.261 & 0.286 & -7.916 & $<0.001$ \\
\hline
\end{tabular}

and by-participant random slopes for the stimulus type was found to perform best $\left[\chi^{2}=69.481, \mathrm{df}=2, p<0.001\right]$. The results showed that the stimulus type (target or control) is a reliable predictor for participants' response, see Table 1.

\subsubsection{Reading and response time}

Participants spent more time reading the target stimuli $[\bar{x}=2364.5 \mathrm{~ms}]$ as well as indicating their responses $[\bar{x}=559.7 \mathrm{~ms}]$ than the control stimuli [reading time: $\bar{x}=2024.1 \mathrm{~ms}$; response time: $\overline{\mathrm{x}}=445.7 \mathrm{~ms}$, see Figs. 2 and 3.

To investigate the effect of stimulus type (target or control) on participants' reading and response time, we ran a series of linear mixed-effects models using the lmerTest package (Kuznetsova et al., 2013) in $R$ (R Core Team, 2017). For the reading time we first ran a null model with participants' stimuli reading time as a dependent variable, and participants and items as random factors. We then ran a model that included in addition the stimulus type as a fixed effect factor to examine whether the model was improved. Finally, on the basis of the first two models that included participants' stimuli reading time as a dependent variable, the stimulus type as a fixed-effect factor, and participants and items as random factors, allowing by-participant and by-item random intercepts, we ran another three models that in addition allowed by-participant or/and by-item random slopes for the stimulus type. For the response time, we followed a similar procedure to the stimuli reading time. Model fit was compared based on the likelihood ratio test (Pinheiro and Bates, 2000; Bolker et al., 2009) and for both the stimuli reading time and the response time, the model which included by-participant and by-item random intercepts, and by-participant random slopes for the stimuli type was found to perform best [for stimuli reading time, $\chi^{2}=37.384, \mathrm{df}=2$, $p<0.001$; for response time, $\left.\chi^{2}=35.825, \mathrm{df}=2, p<0.001\right]$.

The results showed that participants spent significantly longer time in reading the target stimuli that contained diănr than the control stimuli
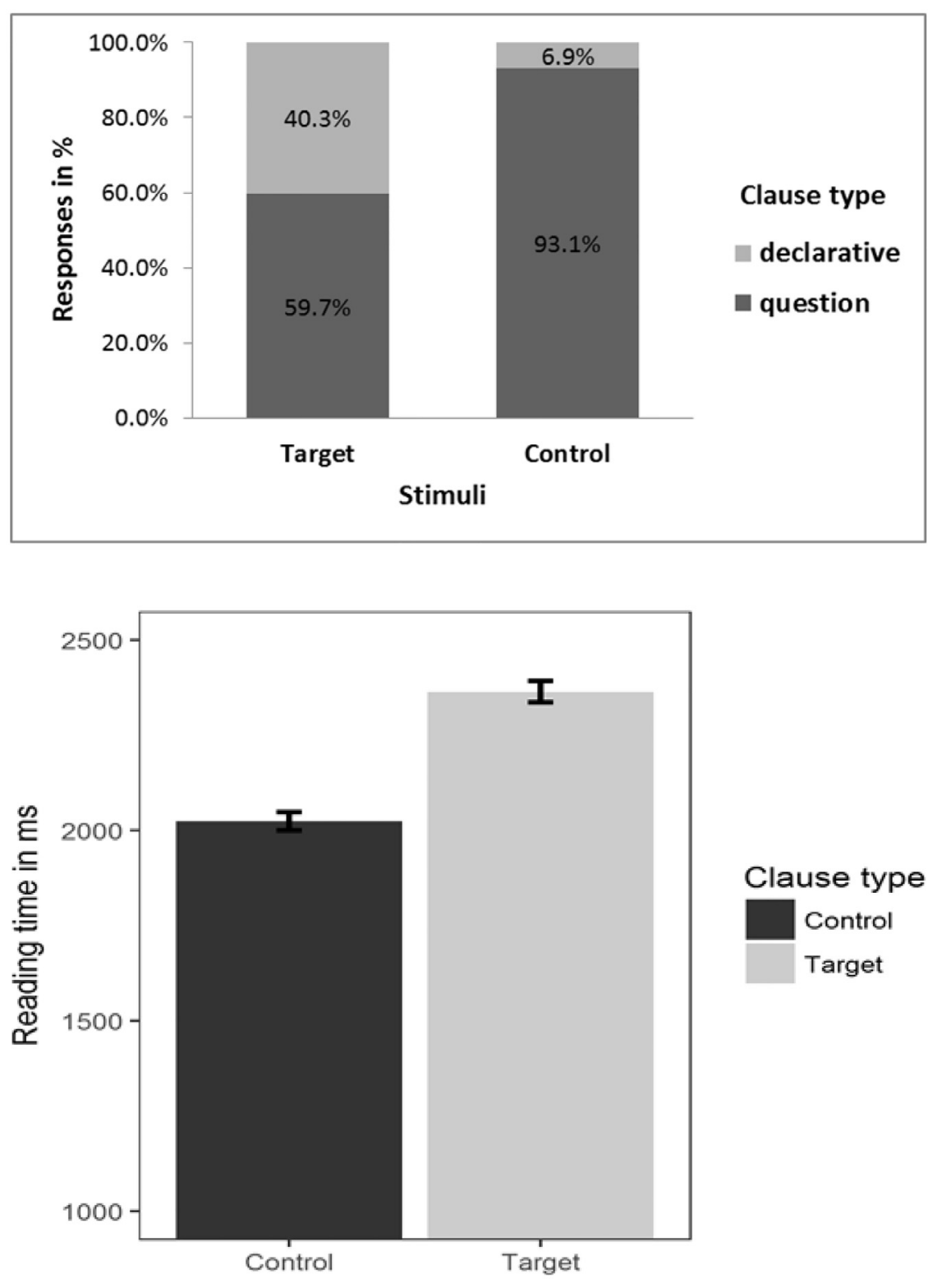

\section{Clause type \\ Control \\ Target}

Fig. 1. Participants' responses in percentage (\%) in the reading study.
Fig. 2. Participants' stimuli reading time with error bars showing standard errors. 


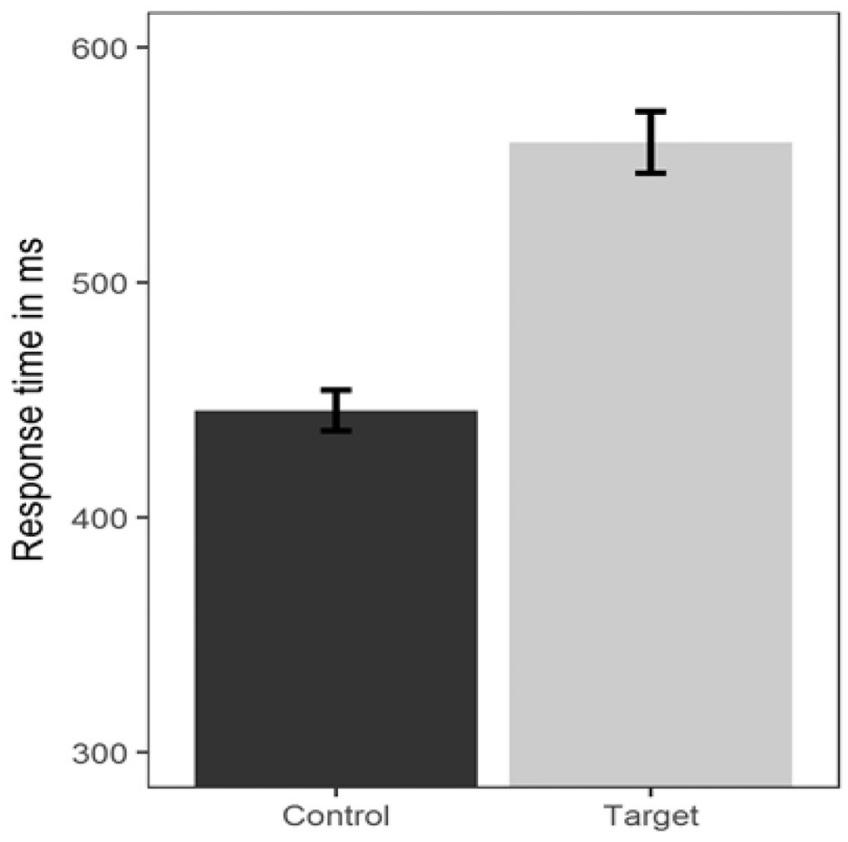

without diǎnr. Participants spent also significantly longer time in indicating the clause type for the target stimuli than the control stimuli, see Table 2.

To summarize, the results show that wh-sentences with diănr like (6a), are ambiguous between a declarative and a question interpretation in the absence of punctuation, context or prosody, as supported by participants' responses in choosing the punctuations. The longer reading time and response time in the target sentences than the control sentences offer further support for the claim that sentences containing diănr followed by a wh-word are ambiguous between wh-questions and wh-declaratives (see Ferreira and Clifton, 1986, among others, for the discussion of a longer processing time on ambiguous cases than unambiguous cases).

After establishing that wh-sentences with diănr are indeed ambiguous in terms of clause types, we conducted a production experiment to investigate the research question (R2) of whether and how prosody is employed to distinguish the two clause types.

\section{Production experiment}

\subsection{Method}

\subsubsection{Participants}

Forty native speakers of Beijing Mandarin (23 females and 17 males, $\bar{x}$ age $=21$ years old, $\mathrm{SD}=2.53$ ) who were born and raised in Beijing were paid to participate in the experiment. None of these participants have participated in the reading study or any other similar studies. At the time of recording these participants were students at Tsinghua University. None of them reported speech problems or visual impairment. Prior to recording, informed written consent was obtained from each participant.

\section{Table 2}

Summary of the results of the linear mixed-effects models on participants' stimuli reading time and response time.

\begin{tabular}{lcccc}
\hline & Estimate $\beta$ & Std. Error & $t$ value & $p$ value \\
\hline Stimuli reading time & -341.093 & 41.654 & -8.189 & $<0.001$ \\
Response time & -114.384 & 18.234 & -6.273 & $<0.001$ \\
\hline
\end{tabular}

Fig. 3. Participants' response time in indicating the clause types with error bars showing standard errors.

\section{Clause type \\ Control \\ Target}

\subsubsection{Materials}

We created a total of 56 stimuli; half of the stimuli were whdeclaratives (see example in 7a), while the other half were wh-questions (see example in 7b). Wh-declaratives were string identical to their corresponding wh-questions except for the punctuation at the end of the sentence. As shown in (7), we used the word order which is essentially the same as the reading study: Subject (proper name, e.g. Táo Weì), Adverb (e.g. zúotiān 'yesterday'), Verb (e.g. ná 'bring') + Perfective marker (le), (diănr), Direct Object (shénme 'what/something'), and Prepositional Phrase (e.g. gěi Líu Gāng 'to/for Liu Gang'). Each stimulus was 12 syllables long and the stimulus length was kept constant across clause types and items. We also kept constant the combination of tones across clause types and items for all the constituents, but the verb. For the verb, we included all four lexical tones, to obtain enough natural stimuli for the experiment. An example of a stimulus set is given in (7).

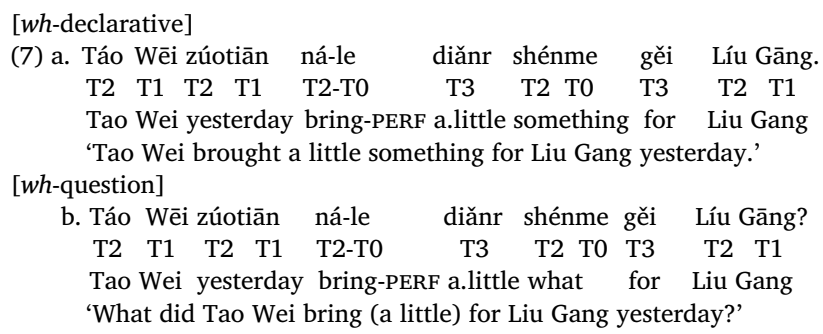

\subsubsection{Procedure}

The recordings took place in a sound-proof booth in a lab of the Department of Foreign Languages and Literatures at Tsinghua University in Beijing. For the recordings, we used a head-worn unidirectional dynamic microphone (Shure SM10A) which was connected to an external sound card (UA-1 G), and Audacity software (sampling rate $44.1 \mathrm{kHz}, 16$ bit, mono). The stimuli were presented on screen without any preceding context using Praat (Boersma and Weenink, 2017) and the presentation pace of each stimulus was controlled by the experimenter. Participants were instructed to silently read the stimulus on screen to understand its meaning, and then to utter it as if they were talking with someone. Participants were not forced to read the sentences under any time pressure. Once they had uttered the sentence, the new stimulus appeared 


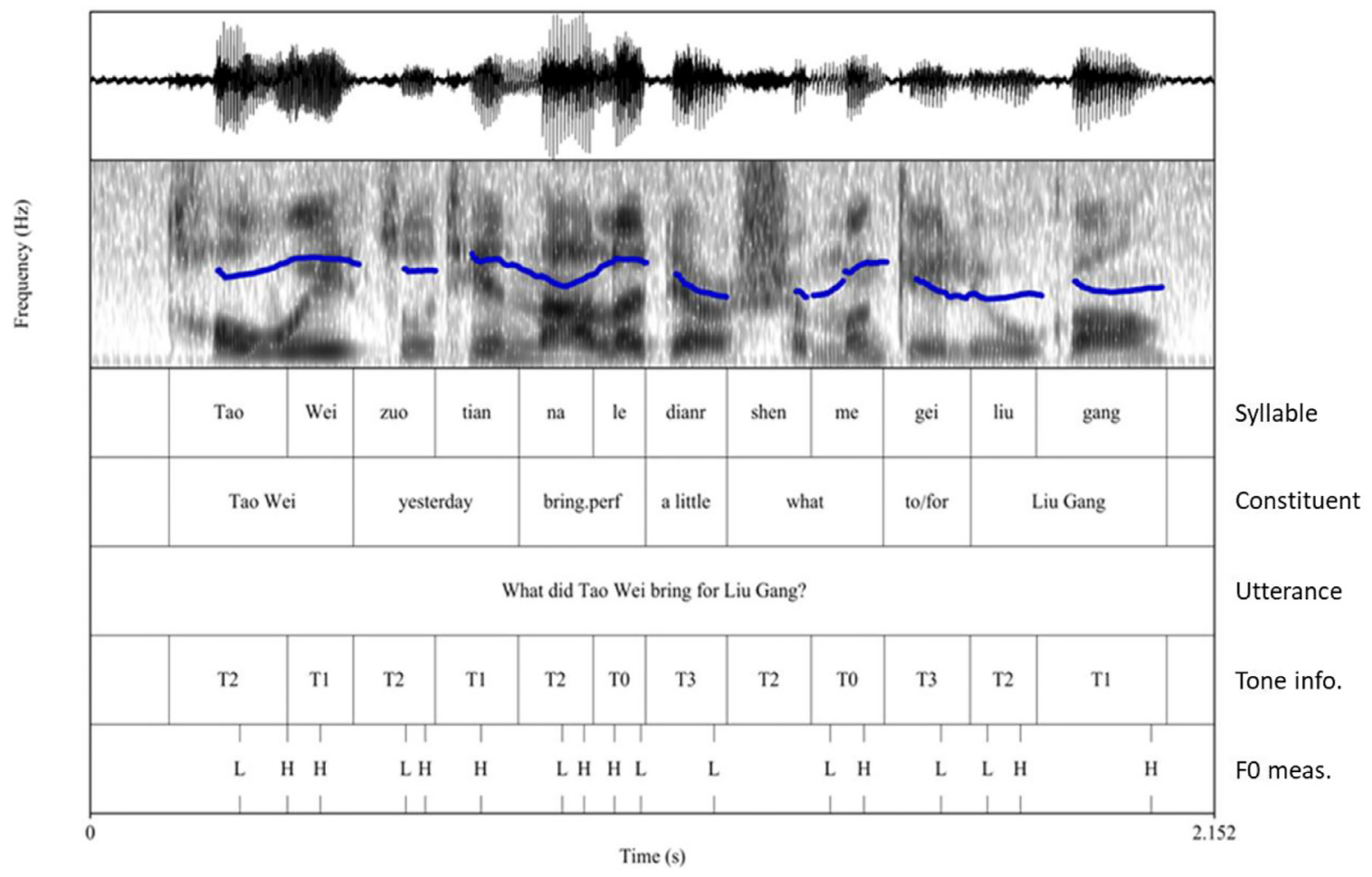

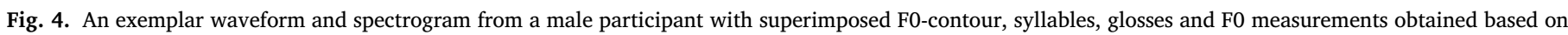
the specific tones.

on screen. A pseudo-randomized list of stimuli was prepared for every participant to avoid any ordering effects.

\subsubsection{Acoustic analysis}

We recorded a total of 2240 utterances ( 40 participants $\times 56$ stimuli). 338 utterances were excluded from any further analysis due to slips of the tongue, disfluencies and unnatural pausing. The remaining 1902 stimuli were manually annotated using Praat (Boersma and Weenink, 2017), as shown in Fig. 4. We obtained the following measurements using a number of Praat scripts.

\subsubsection{Duration}

(i) Utterance duration in ms

(ii) Word duration in ms; this was calculated based on the syllable duration, see Fig. 4. When the initial was a stop, we measured the stop from the beginning of the release burst.

\subsubsection{FO}

In Mandarin, a lexical tone is encoded by a pitch pattern (Xu, 2001; Xu and Wang, 2001). Following Duanmu (2004) (see also van de Weijer and Sloos, 2014) we used H(igh) and L(ow) to operationalize the representation of the four lexical tones (T) in Mandarin. Hence, T1 is a high level tone and is represented as $\mathrm{H}, \mathrm{T} 2$ is a rising tone and is represented as LH, T3 is a low tone represented as L and T4 is a falling tone represented as HL. We measured the following F0 points.

(iii) F0-maximum $(\mathrm{H})$ of the syllable that bore $\mathrm{T} 1$ (high level tone)

(iv) F0-minimum and then F0-maximum (LH) of the syllable that bore T2 (rising tone)

(v) F0-minimum (L) of the syllable that bore T3 (low tone)

(vi) F0-maximum and then F0-minimum (HL) of the syllable that bore T4 (falling tone)

(vii) For T0 (neutral tone) of the perfective marker le, following $\mathrm{Li}$ (2002), we measured first the F0-maximum and then the F0minimum, when the preceding syllable (verb) bore T1, T2 or T4.
On the other hand, we measured first the F0-minimum and then the F0-maximum, when the preceding syllable bore Tone 3. For the second syllable of the wh-word shénme, namely, me, when found in isolation it bears Tone 0. However, in our data, it behaved like a rising tone (T2); thus we treated it as such, measuring the F0-minimum and then the F0-maximum.

The obtained F0 values in $\mathrm{Hz}$ were converted into semitones (ST) to reduce variation across speakers; following Li and Chen (2012), for female speakers we used formula (i) ST $=12 \log 2(\mathrm{~Hz} / 100)$, while for male speakers we used formula (ii) $\mathrm{ST}=12 \log 2(\mathrm{~Hz} / 50)$.

\subsubsection{FO range}

We also calculated the F0 range in ST of the wh-word (shénme), and the post wh-word region, following previous studies (Dong, 2009; Liu et al., 2016).

(viii) F0 range of shén and me: Given that shén is a rising tone and that $m e$ also behaves like a rising tone, we calculated the F0 range of shén and me respectively, shén as F0-maximum of shén - F0minimum of shén and me as F0-maximum of me - F0-minimum of $m e$.

(ix) F0 range of post-wh-word region, namely, the prepositional phrase (PP) (e.g. gěi plus indirect object Líu Gāng "to/for Liu Gang"). Given that gěi carries a low tone, and that the first syllable of the indirect object bears a rising tone and the second syllable a high tone, the pitch contour in the whole prepositional phrase is in general a rising contour. Hence we calculated the F0 range of the prepositional phrase as F0-maximum of the second syllable of the indirect object (e.g. Gāng) - F0-minimum of gěi. See Fig. 5.

\subsection{Intensity range}

(x) Intensity range of each syllable defined as MaximumIntensity-(minus) Minimum-Intensity (Chen, 2005; Ouyang and Kaiser, 2015), see Fig. 6. 


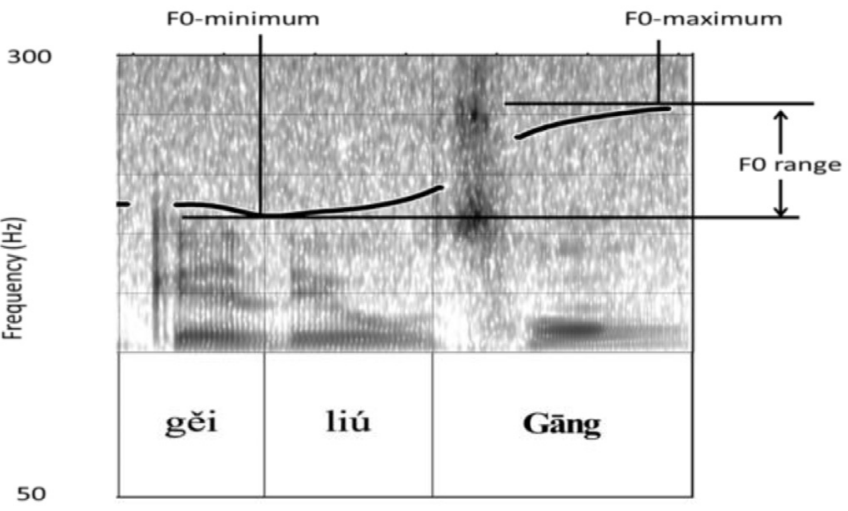

Fig. 5. The F0 contours of the PP and its F0-range obtained.
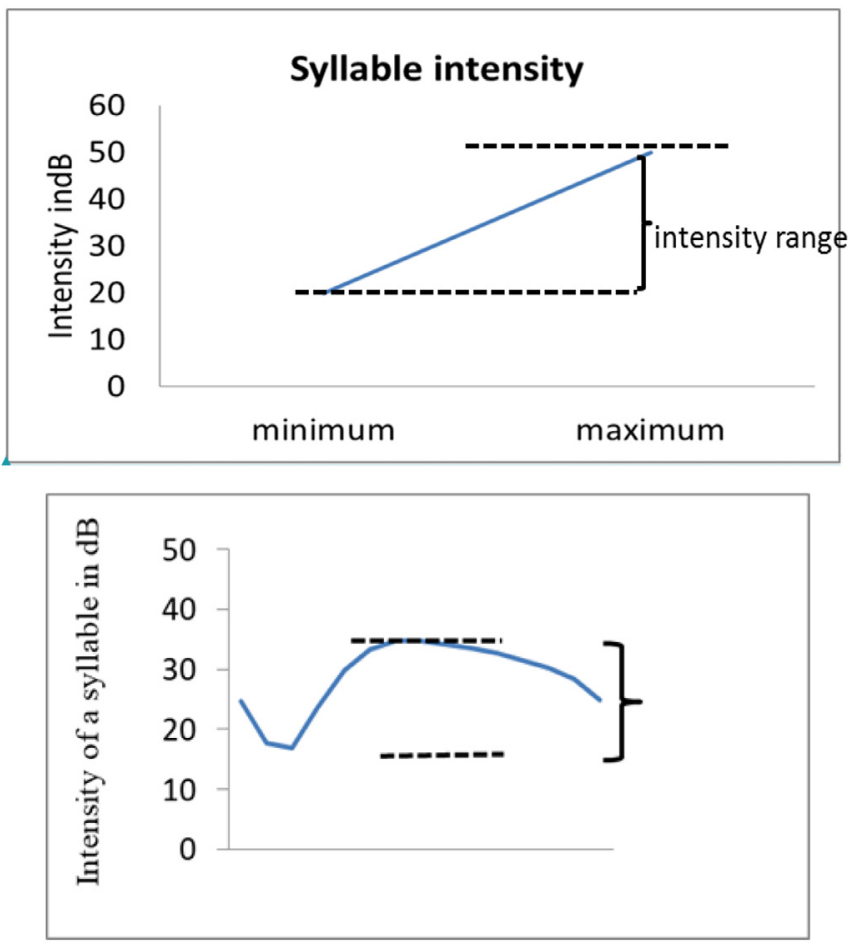

Fig. 6. Intensity range measurement of each syllable.

\subsection{Statistical analysis}

We ran a series of linear mixed-effects models using the lmerTest package (Kuznetsova et al., 2013) in $R$ (R Core Team, 2017). Specifically, for every measurement, we first ran a null model with the relevant measurement as the dependent variable, and participants and items as random factors. A second model included in addition clause type as a fixed effect factor. Finally, for each measurement, on the basis of the first two models that included the relevant measurement as a dependent variable, the clause type as a fixed-effect factor, and participants and items as random factors, allowing by-participant and by-item random intercepts, we ran another three models that in addition allowed by-participant or/and by-item random slopes for clause type. Model fit was compared based on the likelihood ratio test for each measurement (Pinheiro and Bates, 2000; Bolker et al., 2009); see Appendix A for the details of the fitting models in each measurement and their model fit comparison results.

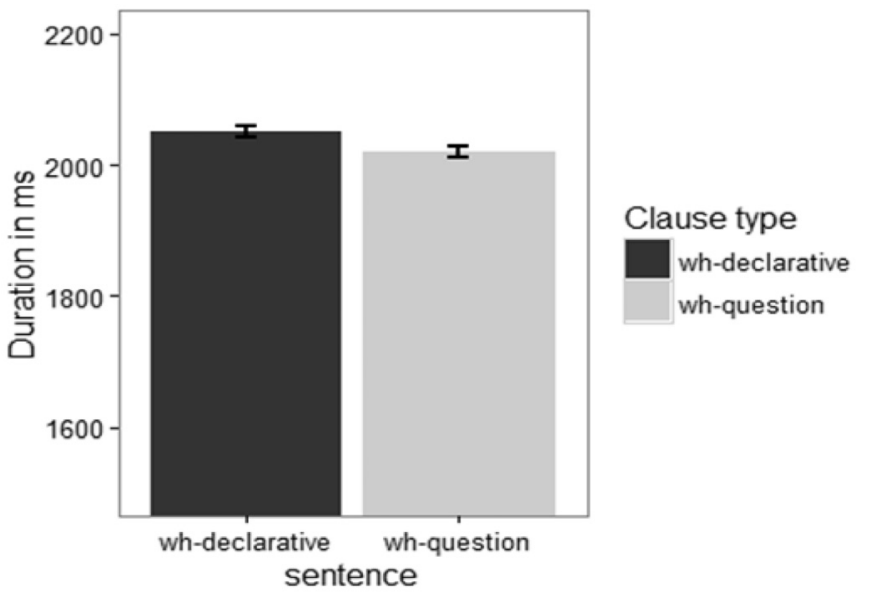

Fig. 7. Mean sentence duration in ms with error bars showing standard error across clause types.

\subsection{Results}

\subsubsection{Utterance duration}

We found an effect of clause type on utterance duration; whdeclaratives $[\bar{x}=2050 \mathrm{~ms}]$ are significantly longer than wh-questions $[\bar{x}=2020 \mathrm{~ms}]$; see Fig. 7 .

\subsubsection{Word duration}

Fig. 8 presents the mean duration of all words in the utterance. We found an effect of clause type on the duration of the Subject, of the Verb plus the perfective marker le, of diănr and of the wh-word. Specifically, the duration of the Subject, Verb plus le and diănr in whdeclaratives $(\bar{x}=347 \mathrm{~ms}, \bar{x}=289 \mathrm{~ms}$ and $\bar{x}=171 \mathrm{~ms}$ respectively) are significantly longer than those in wh-questions $(\bar{x}=341 \mathrm{~ms}, \bar{x}=261 \mathrm{~ms}$ and $\bar{x}=166 \mathrm{~ms}$ respectively). The pattern changes when examining the duration of the wh-word shénme. Shénme in wh-declaratives $(\bar{x}=294 \mathrm{~ms})$ is significantly shorter than in wh-questions $(\bar{x}=305 \mathrm{~ms})$. When looking at the post-wh-word region, the prepositional phrase (gěi plus indirect object) in $w h$-declaratives $(\bar{x}=572 \mathrm{~ms})$ does not differ from $w h$ questions $(\bar{x}=572 \mathrm{~ms})$.

In short, wh-declaratives are in general longer in terms of duration than the corresponding $w h$-questions with an exception at the wh-word: the wh-word shénme is longer in duration when it is a question word than when it is an existential meaning something. The detailed results of the mixed effects model can be found in Table 3 .

\subsubsection{FO}

Fig. 9 presents the stylized means of F0 curves of the two clause types broken per verb tone (from $\mathrm{T} 1$ to $\mathrm{T} 4$ ). As is shown, the most striking F0 difference between the two clause types is at the wh-word shénme (syllable (S) 8 and (S) 9), which shows a steep rise in wh-questions but is relatively flat in wh-declaratives, and the F0 in wh-questions remains higher than that in wh-declaratives until the end of sentence. To be specific, shénme in wh-declaratives has lower F0 at the F0-mimimum of

Table 3

Summary of the linear mixed effects models on the durations.

\begin{tabular}{lllll}
\hline & Estimate $\beta$ & Std. Error & $t$ value & $p$ value \\
\hline Subject & 5.626 & 1.860 & 3.024 & $<0.01$ \\
Adverb & 1.146 & 3.039 & 0.377 & $>0.1$ \\
verb-le & 27.993 & 2.730 & 10.253 & $<0.001$ \\
diănr & 5.339 & 1.239 & 4.310 & $<0.001$ \\
shénme & -11.065 & 3.588 & -3.084 & $<0.01$ \\
Preposition phrase & -0.397 & 3.818 & -0.104 & $>0.1$ \\
\hline
\end{tabular}




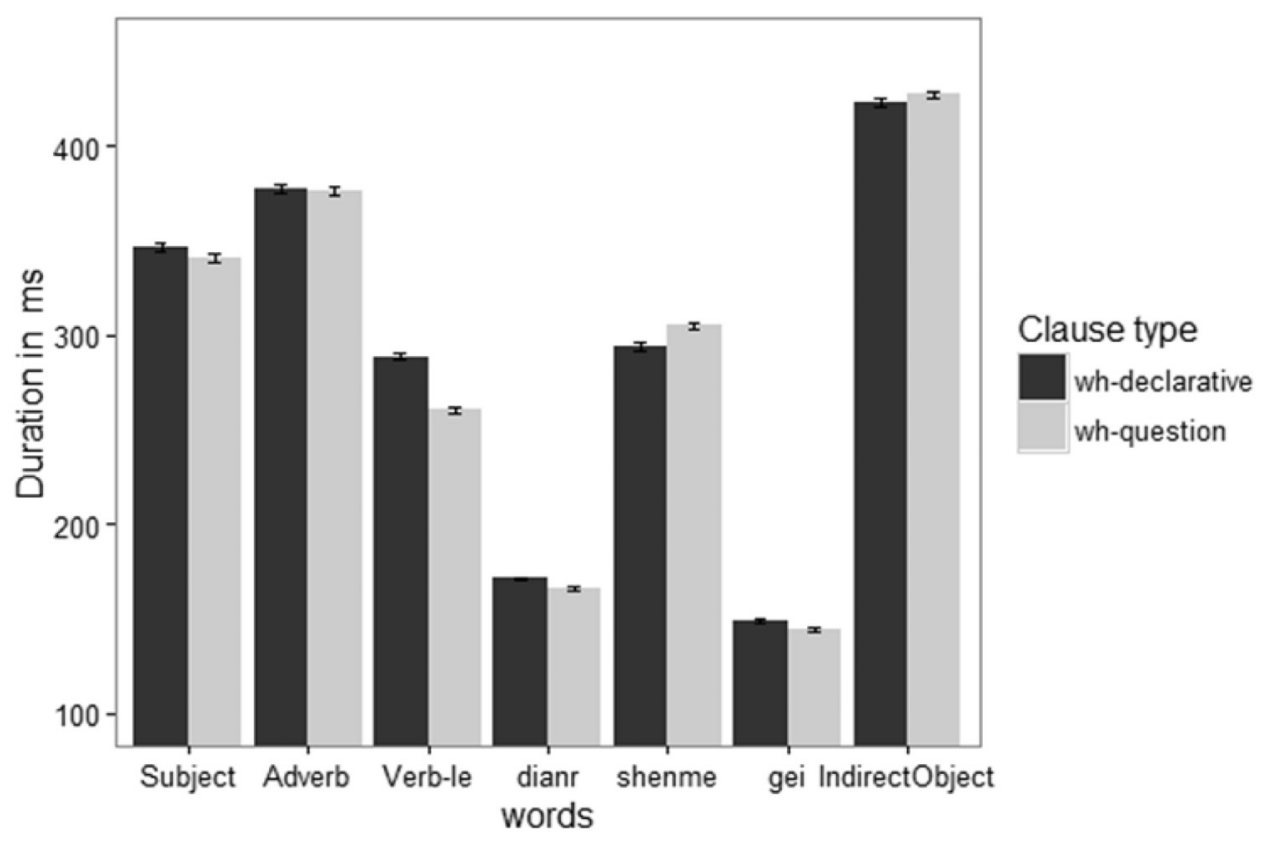

Fig. 8. Mean word duration in ms with error bars showing standard error across clause types.

shén $(\bar{x}=9.964 \mathrm{ST})$, the F0-minimum of $m e(\bar{x}=10.462 \mathrm{ST})$ and the F0-maximum of $m e(\bar{x}=12.392 \mathrm{ST})$ than in wh-questions $(\bar{x}=10.579$ ST for F0-mimimum of shén, $\bar{x}=12.008$ ST for F0-minimum of me and $\bar{x}=17.625 \mathrm{ST}$ for F0-maximum of $m e$ ).

In the pre-wh-word region, we also found F0 differences at the verb when it bears T2. The F0-minimum and F0-maximum of the T2 verb in wh-declaratives $(\bar{x}=11.947 \mathrm{ST}, \bar{x}=13.929 \mathrm{ST})$ are lower than that of wh-questions ( $\bar{x}=13.274 \mathrm{ST}, \bar{x}=15.465 \mathrm{ST})$ respectively. In the postwh-word region, wh-declaratives are continuously lower in F0 than in $w h$-questions. To be specific, the F0-minimum of gěi in wh-declaratives $(\bar{x}=8.820 \mathrm{ST})$ is lower than that in wh-questions $(\bar{x}=12.036 \mathrm{ST})$; the F0-miminum and F0-maximum of the first syllable of the indirect object in $w h$-declaratives $(\bar{x}=7.601 \mathrm{ST}, \bar{x}=10.262 \mathrm{ST})$ are also lower than that in wh-questions ( $\bar{x}=10.328 \mathrm{ST}, \bar{x}=12.017 \mathrm{ST}$ ); finally, the F0maximum of the second syllable of the indirect object in wh-declaratives $(\bar{x}=13.327 \mathrm{ST})$ is again lower that in wh-questions $(\bar{x}=14.560 \mathrm{ST})$. The detailed results of the mixed effects model can be found in Table 4 .

\subsubsection{FO range}

The F0 range differences between clause types were found at the $w h$-word and the post-wh-word region. The F0 range of me in wh-declaratives $(\bar{x}=1.930 \mathrm{ST})$ is smaller than that in wh-questions $(\bar{x}=5.617$ ST). The F0 range of the prepositional phrase after the $w h-$ word is bigger in wh-declaratives $(\bar{x}=4.507 \mathrm{ST})$ as compared with that in wh-questions $(\bar{x}=2.524 \mathrm{ST})$, indicating a compressed F0 range in the

\section{Table 4}

Summary of the linear mixed effects models on the F0 measurements with significant differences between clause types.

\begin{tabular}{lclll}
\hline & Estimate $\beta$ & Std. Error & $t$ value & $p$ value \\
\hline F0-min shén & -0.714 & 0.171 & -4.167 & $<0.001$ \\
F0-min me & -1.630 & 0.263 & -6.199 & $<0.001$ \\
F0-max me & -5.298 & 0.393 & -13.468 & $<0.001$ \\
F0-min verb (T2) & -1.351 & 0.541 & -2.497 & $<0.05$ \\
F0-max verb (T2) & -1.561 & 0.265 & -5.894 & $<0.001$ \\
F0-min gěi & -3.355 & 0.438 & -7.661 & $<0.001$ \\
F0-min indirect object(1st syllable) & -2.714 & 0.426 & -6.365 & $<0.001$ \\
F0-max indirect object (1st syllable) & -1.817 & 0.237 & -7.659 & $<0.001$ \\
F0-max indirect object (2nd syllable) & -1.364 & 0.310 & -4.401 & $<0.001$ \\
\hline
\end{tabular}

post-wh-word region of $w h$-questions. The detailed results of the mixed effects model can be found in Table 5 .

\subsubsection{Intensity range}

Fig. 10 shows the mean intensity range of each syllable (S) across the two clause types. As illustrated in the Fig. 10, the main differences between wh-declaratives and wh-questions are at the verb-le (S5 and S6), the wh-word shénme (S8 and S9) and gěi (S10). Wh-declaratives have a bigger intensity range at the verb $(\bar{x}=20.210 \mathrm{~dB})$ and at $l e(\bar{x}=7.701 \mathrm{~dB})$ than wh-questions $(\bar{x}=19.079 \mathrm{~dB}, \bar{x}=6.865 \mathrm{~dB})$. The direction changes when looking at the $w h$-word. Shén and me in wh-declaratives are significantly smaller in intensity range $(\bar{x}=9.477 \mathrm{~dB}, \bar{x}=7.745 \mathrm{~dB})$ than those in $w h$-questions $(\bar{x}=10.095 \mathrm{~dB}, \bar{x}=9.470 \mathrm{~dB})$. Finally, for the prepositional phrase after the wh-word, we only find intensity range differences at gěi, which is smaller in $w h$-declaratives $(\bar{x}=15.315 \mathrm{~dB})$ than that in $w h$-questions $(\bar{x}=17.966 \mathrm{~dB})$. The detailed results of the linear mixed effects model are summarized in Table 6.

Table 5

Summary of the linear mixed effects models on F0 range with significant differences between clause types.

\begin{tabular}{lllll}
\hline & Estimate $\beta$ & Std. Error & $t$ value & $p$ value \\
\hline F0 range me & -3.653 & 0.274 & -13.346 & $<0.001$ \\
F0 range preposition phrase & 1.975 & 0.487 & 4.054 & $<0.001$ \\
\hline
\end{tabular}

Table 6

Summary of the linear mixed effects models on the intensity range with significant differences between clause types.

\begin{tabular}{lllll}
\hline & Estimate $\beta$ & Std. Error & $t$ value & $p$ value \\
\hline verb & 1.119 & 0.179 & 6.243 & $<0.001$ \\
le & 0.833 & 0.224 & 3.713 & $<0.001$ \\
shén & -0.620 & 0.157 & -3.963 & $<0.001$ \\
me & -1.729 & 0.351 & -4.927 & $<0.001$ \\
gěi & -2.662 & 0.461 & -5.767 & $<0.001$ \\
\hline
\end{tabular}



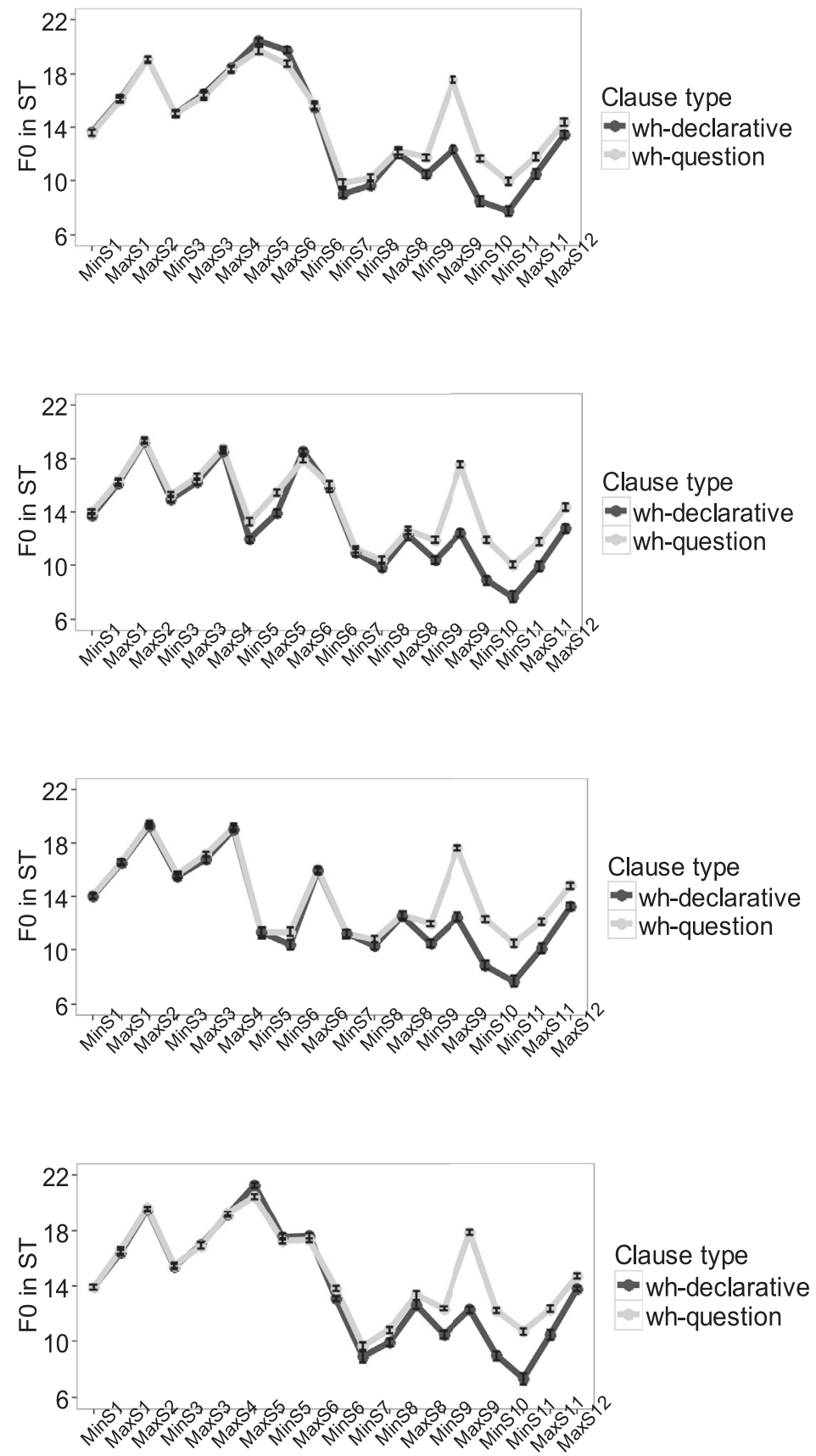

\section{Discussion and conclusions}

The starting point of our studies is a new and interesting observation that $w h$-sentences containing diănr is ambiguous between wh-questions and $w h$-declaratives ( $w h$-word has an existential interpretation), challenging previous studies which claim that the existential interpretation of a wh-word is available only in nonveridical sentences. To empirically test this observation, we conducted a reading study on $w h$-sentences containing diănr. Another related question concerns how string identical $w h$-questions and wh-declaratives are distinguished prosodically. By reviewing previous studies, we found that an important knowledge gap still remains with respect to the detailed prosodic differences between Mandarin wh-declaratives and wh-questions. We therefore conducted a production study on wh-declaratives and wh-questions, examining the prosodic properties of each clause type.
Fig. 9. Stylized means of F0 curves in ST across clause types with error bars showing standard errors; Min indicating the Minimum F0 measurement and Max indicating the Maximum F0 measurement.

The stylized mean F0 curve is based on our F0 measurement as illustrated in Fig. 2, namely we use a F0-maximum to represent T1(H), F0-mimimum and F0-maximum to represent T2(LH), F0-minimum to represent T3(L), and for T4(HL) we use F0-maximum and F0-mimimum. 


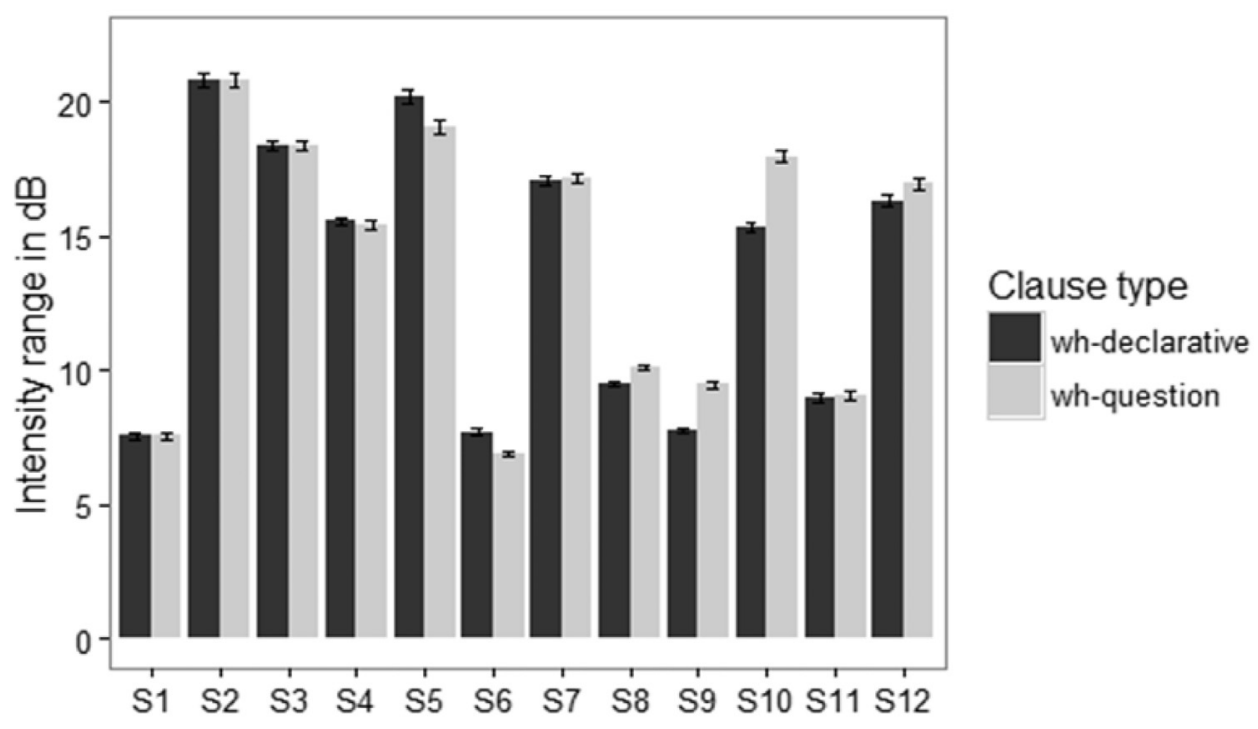

Fig. 10. Mean intensity range of each syllable (S) across clause types with error bars showing standard errors. ration than the corresponding wh-questions in general. As for F0, consistent with previous studies, wh-words in wh-questions exhibit a steep F0 rise and expanded F0 range (Hu, 2002; Lee, 2005; Dong, 2009; Liu, 2009, 2016) The findings on F0 are also consistent with previous studies claiming that the presence of a high pitch is often a property of question intonation cross-linguistically (van Heuven and van Zanten, 2005). In addition to F0, wh-words present a longer duration and a bigger intensity range in wh-questions than $w h$-words used in wh-declaratives.

Moreover, we find that duration not only marks the clause type, but also marks it "early". As shown in the results of the production experiment, it is mainly duration that provides an early cue to differentiate the two interpretations from the onset of the utterance (sentence subject), with $w h$-declaratives always longer than wh-questions and at the verb-le the difference reaches the peak. This early durational property (a shorter duration in wh-questions as opposed to declaratives) can be considered as another important feature of Mandarin wh-questions, in addition to the commonly known higher F0. This finding of the duration property is in general consistent with studies of other languages reporting that duration plays a role in marking questions (Lindsey, 1985; van Heuven and van Zanten, 2005; Cangemi and D'Imperio, 2013). In the post-whword region, wh-questions show a long-lasting higher pitch and their F0 range is smaller than that in wh-declaratives, indicating a typical F0 compression after wh-words in wh-questions. In addition to the above findings on the different prosodic markings of the two clause types, our production results also shed light on the discussion of the focal property of $w h$-words and their prosodic realization. Following the approach to focus proposed by Jacobs $(1984,1991)$, the partition of content into focus and ground is related to illocutionary semantics: focus is defined as the part of the sentence that is specifically affected by the sentence's illocutionary operator. According to this, in a wh-question, which is an information-seeking question, the interrogative $w h$-word is typically a focus (see Cho, 1990; Lambrecht and Michaelis, 1998; Deguchi and Kitagawa, 2002; Ishihara, 2002, among others), while in a wh-declarative, where the wh-word is a narrow scope indefinite 'something' and normally cannot be affected by any illocutionary operator, is not a focus. Our production results provide further support to identifying the different focus status of $w h$-words in wh-questions in contrast with $w h$-words in wh-declaratives in Mandarin.

It should be noted that different languages may have different ways to realize focus, ranging from morpho-syntactic markers to prosodic means. For those languages that have a general correspondence between focus and the prosodic marking, focused constituents are typically characterized with an expanded pitch range and the post-focal regions typically show a compressed F0 range (for Germanic languages, see Cruttenden, 2006, Fery and Kügler, 2008, among others; for Mandarin studies, see Xu, 1999; Yuan, 2004; Li, 2009; Chen, 2010; Xu et al., 2012, among others). In addition, a focused element quintessentially has a longer duration and greater intensity (Xu, 1999; Chen et al., 2009; Li, 2009). In our production study, we found that wh-questions have a raised and expanded F0 range, lengthened duration and greater intensity range at the interrogative wh-word shénme and an F0 range compression after shénme, consistent with the prosodic markings of focus in Mandarin. In contrast, our study reveals that non-interrogative $w h$-words in wh-declaratives are largely suppressed with an almost flat pitch, a short duration and a small intensity range, inconsistent with the prosodic realizations of a focus in Mandarin. The different prosodic realizations of the $w h$-words in $w h$-questions and $w h$-declaratives serve as additional evidence that $w h$-words have different focal properties as a question word in wh-questions as compared with an indefinite in whdeclaratives. To conclude, in this study we have established that sentences containing diănr followed by a $w h$-word are indeed ambiguous between $w h$-questions and wh-declaratives, countering to previous studies. Furthermore, we have uncovered that wh-questions and wh-declaratives are distinguished by prosody, supporting the role of prosody in marking clause types in the absence of an overt syntactic interrogativity marker (Bolinger, 1978; Ohala, 1983, 1984; Jun and Oh, 1996; Frota, 2002; Face, 2004; Vion and Colas, 2006; Baltazani, 2007). Our production results have demonstrated that $w h$-questions and $w h$-declaratives differ in various prosodic properties, not limited to F0; it is duration that marks the two clause types early as wh-declaratives are continuously longer than wh-questions in terms of word duration since the onset of the sentence (subject). The current study also indicates that wh-questions and wh-declaratives differ in terms of the information structure; in particular, a wh-word in Mandarin is a focus when it is a question word (e.g., 'what'), but it is not a focus when it is an indefinite (interpreted as an existential 'something') used in a wh-declarative.

\section{Declaration of Competing Interest}

None.

\section{Acknowledgments}

We thank Xiaolu Yang for assistance in conducting the recording experiment and Jos Pacilly for assistance in writing Praat scripts. We also thank Leticia Pablos, Jenny Doetjes and Aliza Glasbergen-Plas for their comments and discussions during the whole process of experimental design and data analysis. The study was presented in the 2 nd International 
Conference on Chinese Prosodic Grammar and we thank Laura Downing, San Duanmu, Eric Zee and Dylan Tsai for their useful comments.

\section{Funding}

This study was supported by a project granted by the Philosophy and Social Science Foundation of Guangdong Province [grant number GD19YYY03] and a project granted by Guangzhou Philosophy and Social Science Foundation [grant number 2019GZGJ66] on the first author and was also funded by the NWO project Understanding Questions [project number 360-70-480] on the second author.

\section{Appendix A}

Summary of all the fitting models on prosodic measurements where the clause type has an effect and their model fit comparison results.

\begin{tabular}{|c|c|c|}
\hline Measurement & The fitting model & $\begin{array}{l}\text { Model fit } \\
\text { comparisons }\end{array}$ \\
\hline $\begin{array}{l}\text { Utterance } \\
\text { speaking rate }\end{array}$ & $\begin{array}{l}\text { SpeakRate <- lmer (SpeakRate } \sim \\
\text { condition }+(\text { condition } \mid \text { sub })+(1 \mid \text { item }), \\
\text { data=data })\end{array}$ & $\begin{array}{l}\chi^{2}=15.148, \mathrm{df} \\
=2, p<0.001\end{array}$ \\
\hline $\begin{array}{l}\text { Utterance } \\
\text { duration }\end{array}$ & $\begin{array}{l}\text { Utterance }<- \text { lmer }(\text { Utterance } \sim \text { condition } \\
+(\text { condition } \mid \text { subject })+(1 \mid \text { item }) \\
\text { data=data })\end{array}$ & $\begin{array}{l}\chi^{2}=15.148, \mathrm{df} \\
=2, p<0.001\end{array}$ \\
\hline \multicolumn{3}{|l|}{ Word duration } \\
\hline subject & $\begin{array}{l}\text { Word <- lmer }(\text { duration } \sim \text { condition }+ \\
(1 \mid \text { subject })+(1 \mid \text { item }), \text { data=data })\end{array}$ & $\begin{array}{l}\chi^{2}=9.128, \mathrm{df} \\
=1, p<0.01\end{array}$ \\
\hline verb-le & $\begin{array}{l}\text { Word <- lmer (duration } \sim \text { condition }+ \\
\text { (condition } \mid \text { subject })+(\text { condition } \mid \text { item }) \\
\text { data=data })\end{array}$ & $\begin{array}{l}\chi^{2}=48.028, \mathrm{df} \\
=2, p<0.001\end{array}$ \\
\hline diănr & $\begin{array}{l}\text { Word }<- \text { Imer }(\text { duration } \sim \text { condition }+ \\
(\text { condition } \mid \text { subject })+(1 \mid \text { item }), \text { data }=\text { data })\end{array}$ & $\begin{array}{l}\chi^{2}=23.857, \mathrm{df} \\
=2, p<0.001\end{array}$ \\
\hline shénme & $\begin{array}{l}\text { Word <- lmer }(\text { duration } \sim \text { condition }+ \\
(\text { condition } \mid \text { subject })+(1 \mid \text { item }), \text { data=data })\end{array}$ & $\begin{array}{l}\chi^{2}=109.43, \mathrm{df} \\
=2, p<0.001\end{array}$ \\
\hline \multicolumn{3}{|c|}{ 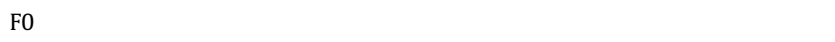 } \\
\hline F0-min shén & $\begin{array}{l}\text { F0 <- } \operatorname{lmer}(\mathrm{F} 0 \sim \text { condition }+ \\
(\text { condition } \mid \text { subject })+(1 \mid \text { item }), \text { data=data })\end{array}$ & $\begin{array}{l}\chi^{2}=10.597, \mathrm{df} \\
=2, p<0.01\end{array}$ \\
\hline F0-min me & $\begin{array}{l}\text { F0 <- Imer }(\text { F0 } \sim \text { condition }+ \\
(\text { condition } \mid \text { subject })+(1 \mid \text { item }), \text { data=data })\end{array}$ & $\begin{array}{l}\chi^{2}=63.800, \mathrm{df} \\
=2, p<0.001\end{array}$ \\
\hline F0-max me & $\begin{array}{l}\text { F0 <- lmer }(\text { F0 } \sim \text { condition }+ \\
(\text { condition } \mid \text { subject })+(1 \mid \text { item }), \text { data }=\text { data })\end{array}$ & $\begin{array}{l}\chi^{2}=199.67, \mathrm{df} \\
=2, p<0.001\end{array}$ \\
\hline $\begin{array}{l}\text { F0-min verb } \\
\text { (T2) }\end{array}$ & $\begin{array}{l}\text { F0 }<-\operatorname{lmer}(\mathrm{F} 0 \sim \text { condition }+(1 \mid \text { subject }) \\
+(\text { condition } \mid \text { item }), \text { data }=\text { data })\end{array}$ & $\begin{array}{l}\chi^{2}=6.763, \mathrm{df} \\
=0, p<0.001\end{array}$ \\
\hline F0-max verb & F0 <- Imer $($ F0 $\sim$ condition $+(1 \mid$ subject $)$ & $\chi^{2}=33.280, \mathrm{df}$ \\
\hline F0-min gěi & $\begin{array}{l}\text { F0 <- Imer }(\text { F0 } \sim \text { condition }+ \\
\text { (condition } \mid \text { subject })+(1 \mid \text { item }), \text { data=data })\end{array}$ & $\begin{array}{l}\chi^{2}=116.00, \mathrm{df} \\
=2, p<0.001\end{array}$ \\
\hline $\begin{array}{l}\text { F0-min } \\
\text { indirect object } \\
\text { (1st syllable) }\end{array}$ & $\begin{array}{l}\text { F0 <- Imer }(\text { F0 } \sim \text { condition }+ \\
(\text { condition } \mid \text { subject })+(1 \mid \text { item }), \text { data }=\text { data })\end{array}$ & $\begin{array}{l}\chi^{2}=80.000, \mathrm{df} \\
=2, p<0.001\end{array}$ \\
\hline $\begin{array}{l}\text { F0-max } \\
\text { indirect object } \\
\text { (1st syllable) }\end{array}$ & $\begin{array}{l}\text { F0 <- Imer }(\text { F0 } \sim \text { condition }+ \\
\text { (condition } \mid \text { subject })+(1 \mid \text { item }), \text { data=data })\end{array}$ & $\begin{array}{l}\chi^{2}=6.5865, \mathrm{df} \\
=2, p<0.05\end{array}$ \\
\hline $\begin{array}{l}\text { F0-max } \\
\text { indirect object } \\
\text { (2nd syllable) }\end{array}$ & $\begin{array}{l}\text { F0 <- lmer }(\text { F0 } \sim \text { condition }+ \\
(\text { condition } \mid \text { subject })+(1 \mid \text { item }), \text { data=data })\end{array}$ & $\begin{array}{l}\chi^{2}=75.306, \mathrm{df} \\
=2, p<0.001\end{array}$ \\
\hline \multicolumn{3}{|l|}{ F0 range } \\
\hline me & $\begin{array}{l}\text { F0 range }<- \text { lmer }(\text { F0Range } \sim \text { condition }+ \\
(\text { condition } \mid \text { subject })+(1 \mid \text { item }), \text { data }=\text { data })\end{array}$ & $\begin{array}{l}\chi^{2}=130.01, \mathrm{df} \\
=2, p<0.001\end{array}$ \\
\hline $\begin{array}{l}\text { preposition } \\
\text { phrase }\end{array}$ & $\begin{array}{l}\text { F0 range }<- \text { lmer }(\text { FORange } \sim \text { condition }+ \\
(\text { condition } \mid \text { subject })+(1 \mid \text { item }), \text { data }=\text { data })\end{array}$ & $\begin{array}{l}\chi^{2}=148.07, \mathrm{df} \\
=2, p<0.001\end{array}$ \\
\hline \multicolumn{3}{|l|}{ Intensity range } \\
\hline verb & $\begin{array}{l}\text { Intensity <- Imer }(\text { Intensity } \sim \text { condition }+ \\
(1 \mid \text { subject })+(1 \mid \text { item }), \text { data=data })\end{array}$ & $\begin{array}{l}\chi^{2}=38.591, \mathrm{df} \\
=1, p<0.001\end{array}$ \\
\hline le & $\begin{array}{l}\text { Intensity }<- \text { Imer (Intensity } \sim \text { condition }+ \\
(1 \mid \text { subject })+(\text { condition|item }), \text { data }=\text { data })\end{array}$ & $\begin{array}{l}\chi^{2}=15.361, \mathrm{df} \\
=0, p<0.001\end{array}$ \\
\hline shén & $\begin{array}{l}\text { Intensity <- lmer (Intensity } \sim \text { condition }+ \\
\text { (condition|subject })+(1 \mid \text { item }), \text { data=data })\end{array}$ & $\begin{array}{l}\chi^{2}=39.934, \mathrm{df} \\
=2, p<0.001\end{array}$ \\
\hline me & $\begin{array}{l}\text { Intensity <- lmer }(\text { Intensity } \sim \text { condition }+ \\
\text { (condition|subject })+(1 \mid \text { item }), \text { data=data })\end{array}$ & $\begin{array}{l}\chi^{2}=230.86, \mathrm{df} \\
=2, p<0.001\end{array}$ \\
\hline gěi & $\begin{array}{l}\text { Intensity <- lmer (Intensity } \sim \text { condition }+ \\
\text { (condition|subject })+(1 \mid \text { item }), \text { data }=\text { data })\end{array}$ & $\begin{array}{l}\chi^{2}=236.47, \mathrm{df} \\
=2, p<0.001\end{array}$ \\
\hline
\end{tabular}

\section{References}

Baltazani, M., 2007. Intonation of polar questions and the location of nuclear stress. In: Gussenhoven, Greek.In, Riad (Eds.). In: Tones and Tunes, 2. Mouton de Gruyter, Berlin, Germany, pp. 387-405.

Bates, D., Maechler, M., Bolker, B., Walker, S., 2015. Fitting linear mixed-effects models using lme4. J. Stat. Softw. 67, 1-48.

Boersma, P., Weenink, D. (2017). Praat: doing phonetics by computer [Computer program]. Version 6.0.28, retrieved from http://www.praat.org.

Bolinger, D., 1978. In: Intonation Across Languages, 2. Universals of Human Language, pp. 471-524.

Bolker, B.M., Brooks, M.E., Clark, C.J., Geange, S.W., Poulsen, J.R., Stevens, M.H.H., White, J.S.S., 2009. Generalized linear mixed models: a practical guide for ecology and evolution. Trends Ecol. Evol. 24 (3), 127-135.

Cangemi, F., D'Imperio, M., 2013. Tempo and the perception of sentence modality. Lab. Phonol. 4 (1), 191-219.

Chen, S.H., 2005. The effects of tones on speaking frequency and intensity ranges in Mandarin and min dialects. J. Acoust. Soc. Am. 117 (5), 3225-3230.

Chen, S.W., Wang, B., Xu, Y., 2009. Closely related languages, different ways of realizing focus. Interspeech 1007-1010.

Chen, Y., 2010. Post-focus F0 compression - Now you see it, now you don't. J. Phon. 38 (4), 517-525.

Cheng, L.L.S., 2009. On every type of quantificational expression in Chinese. In: Rather, M., Giannakidou, A. (Eds.), Quantification, Definiteness, and Nominalization. Oxford University Press, Oxford, pp. 53-75.

Cho, Y.Y., 1990. Syntax and phrasing in korean. In: Inkelas, S., Zec, D. (Eds.), The Phonology-Syntax Connection. University of Chicago Press, Chicago, pp. 47-62.

Chuang, Y.Y., Fon, J., 2010. The effect of prosodic prominence on the realizations of voiceless dental and retroflex sibilants in Taiwan Mandarin spontaneous speech. In: Proceedings of Speech Prosody, 2010.

Cruttenden, A., 2006. The de-accenting of given information: a cognitive universal. Empir. Approach. Lang. Typol. 20 (8), 311.

Deguchi, M., Kitagawa, Y., 2002. Prosody and wh-questions. NELS 32 73-92.

Dong, H., 2009. Issues in the semantics of Mandarin questions. Cornell University.

Duanmu, S., 2004. Tone and non-tone languages: an alternative to language typology and parameters. Lang. Linguist. 5 (4), 891-923.

Face, T.L., 2004. The intonation of absolute interrogatives in Castilian Spanish. Southwest J. Linguist. 23 (2), 65-80.

Ferreira, F., Clifton, C.J., 1986. The independence of syntactic processing. J. Mem. Lang. $25,348-368$.

Féry, C., Kügler, F., 2008. Pitch accent scaling on given, new and focused constituents in German. J. Phon. 36 (4), 680-703.

Frota, S., 2002. Nuclear falls and rises in European Portuguese: a phonological analysis of declarative and question intonation. Probus 14 (1), 113-146.

Giannakidou, A., Cheng, L.L.S., 2006. (In) definiteness, polarity, and the role of wh-morphology in free choice. J. Semant. 23 (2), 135-183.

Hu, F., 2002. A prosodic analysis of wh-words in standard Chinese. Speech Prosody 2002, International Conference.

Huang, C.-T.James, 1982. Logical Relations in Chinese and the Theory of Grammar. MIT dissertation, Cambridge, MA, U.S.A.

Huang, H.L., 2018. On the role of classifiers in licensing Mandarin existential wh-phrases. Proceedings of Sinn und Bedeutung 21 (1), 567-586.

Ishihara, S., 2002. Invisible but audible wh-scope marking: wh-constructions and deaccenting in Japanese. In: Proceedings of WCCFL 21, pp. 180-193.

Jacobs, J., 1984. Funktionale Satzperspektive und Illokutionssemantik. Linguistische Berichte 91, 25-58.

Jacobs, J., 1991. Implikaturen und 'alte information' in w-Fragen. In: Reis, Marga, Rosengren, Inger (Eds.), Fragesätze Und Fragen. Niemeyer, Tübingen, pp. 201-221.

Jiang, A., Chen, P., 2011. Representation of mandarin intonations: boundary tone revisited. In: Proc. 23rd North American Conference on Chinese Linguistics, 1, pp. 97-109.

Jun, S.A., Oh, M., 1996. A prosodic analysis of three types of wh-phrases in Korean. Lang. Speech 39 (1), 37-61.

Kuznetsova, A., Brockhoff, P.B., \& Christensen, R.H.B. (2013). lmerTest: tests for random and fixed effects for linear mixed effect models (Lmer objects of lme4 package). $\mathrm{R}$ Package Version 2.0-3 [Computer Software].

Lambrecht, K., Michaelis, L., 1998. Sentence accent in information questions: default and projection. Linguist. Philos. 21, 477-544.

Lee, O.J., 2005. The prosody of questions in Beijing Mandarin. The Ohio State University.

Li, A., 2002. Chinese prosody and prosodic labeling of spontaneous speech. Speech Prosody 2002, International Conference.

Li, K., 2009. The information structure of Mandarin Chinese: syntax and prosody. University of Washington.

Li, Q., Chen, Y., 2012. Trisyllabic tone sandhi in Tianjin Mandarin. In: Proceedings of the third international symposium on tonal aspects of languages.

Li, Y.H.A., 1990. Order and Constituency in Mandarin Chinese. Kluwer, Dordrecht, the Netherlands.

Li, Y.H.A., 1992. Indefinite wh in Mandarin Chinese. J. East Asian Linguist. 1 (2), 125-155.

Lin, J.W., 1998. On existential polarity-wh-phrases in Chinese. J. East Asian Linguist. 7 (3), 219-255.

Lin, J., Weerman, F., Zeijlstra, H., 2014. Mandarin shenme as a superweak NPI. Black Book: a festschrift in honor of Frans Zwarts 229-251.

Lindsey, G.A., 1985. Intonation and Interrogation: Tonal Structure and the Expression of a Pragmatic Function in English and other Languages. University of California, Los Angeles.

Liu, F., 2009. Intonation systems of Mandarin and English: A functional approach. University of Chicago. 
Liu, X., Li, A., Jia, Y., 2016. How does prosody distinguish Wh- statement from wh-question? A case study of standard chinese. In: Proceedings of Speech Prosody 2016, pp. 1076-1080.

Ohala, J.J., 1983. Cross-language use of pitch: an ethological view. Phonetica 40 (1), 1-18.

Ohala, J.J., 1984. An ethological perspective on common cross-Language utilization of F0 of voice. Phonetica 41 (1), 1-16.

Ouyang, I.C., Kaiser, E., 2015. Prosody and information structure in a tone language: an investigation of Mandarin Chinese. Lang. Cogn. Neurosci. 30 (1-2), 57-72.

Pinheiro, J.C., Bates, D.M., 2000. Mixed-effects Models in S and SPlus. Springer-Verlag, New York.

R. Core Team (2017). R: a language and environment for statistical computing. Vienna, Austria: R Foundation for Statistical Computing, https://www.R-project.org/.

Shen, J., 1994. Intonation structure and intonation types of chinese. Dialect 4, 221-228.

Shen, X.N.S., 1990. The Prosody of Mandarin Chinese. UC Press, CA.

Shen, X.N.S., 1993. Relative duration as a perceptual cue to stress in mandarin. Lang. Speech 36 (4), 415-433.

Shi, P., 1980. Intonation variations in four types of Mandarin sentences. Lang. Teach. Res. $2,71-81$.

Shin, J.Y., 2005. Wh-constructions in Korean: a lexical account. Tor. Work. Papers Linguist. 25 .

Spivey-Knowlton, M.J., Trueswell, J.C., Tanenhaus, M.K., 1993. Context effects in syntactic ambiguity resolution: discourse and semantic influences in parsing reduced relative clauses. Can. J. Exp. Psychol. Revue Canadienne de Psychologie expérimentale 47 (2), 276.

Tsai, W.T.D., 2010. On the syntax-semantics correspondences of Chinese modals. Zhongguo Yuwen 3, 208-221.
Van de Weijer, J., Sloos, M., 2014. The four tones of Mandarin Chinese: representation and acquisition. Linguist. Netherlands 31 (1), 180-191.

Van Heuven, V., Van Zanten, E., 2005. Speech rate as a secondaryprosodic characteristic of polarity questions in three languages. Speech. Commun. 47, 87-99.

Vion, M., Colas, A., 2006. Pitch cues for the recognition of yes-no questions in French. J. Psycholinguist. Res. 35 (5), 427-445.

Huang, B., Liao, X., 2002. Xiandai Hanyu. China Higher Education Press, Beijing.

Xie, Z., 2007. Nonveridicality and existential polarity wh-phrases in Mandarin. In: Proceedings from the Annual Meeting of the Chicago Linguistic Society, 43, pp. 121-135.

$\mathrm{Xu}, \mathrm{Y} ., 1999$. Effects of tone and focus on the formation and alignment of F0 contours. J. Phon. 27 (1), 55-105.

Xu, Y., 2001. Fundamental frequency peak delay in mandarin. Phonetica 58 (1-2), 26-52.

Xu, Y., Chen, S.W., Wang, B., 2012. Prosodic focus with and without post-focus compression: a typological divide within the same language family? The Linguist. Rev. 29 (1), 131-147.

Xu, Y., Wang, Q.E., 2001. Pitch targets and their realization: evidence from Mandarin Chinese. Speech Commun. 33 (4), 319-337.

Yang, Y., 2018. The Two Sides of Wh-Indeterminates in Mandarin: a Prosodic and Processing Account. Lot Publication, Utrecht, Netherlands.

Yuan, J., 2004. Intonation in Mandarin Chinese: Acoustics, perception, and computational modeling Unpublished doctoral thesis. Cornell University, NY.

Yuan, J., 2006. Mechanisms of question intonation in mandarin. In: Chinese spoken language processing. Springer, Berlin-Heidelberg, Germany, pp. 19-30.

Yun, J., 2012. The deterministic prosody of indeterminates. In: Proceedingsof the 29th West Coast Conference on Formal Linguistics, pp. 285-293.

Zhang, N.N., 2013. Classifier Structures in Mandarin Chinese. Walter de Gruyter, Berlin. 